\title{
CROSS-DISCIPLINARY INTEGRATION AS A HIGH INTENSITY METHOD OF GIFTED STUDENTS' TRAINING
}

(C) 2017

\author{
Timoschuk Nina Alexandrovna, candidate of philological sciences, associate professor, \\ head of Psychology and Pedagogy Department \\ Mikhelkevich Valentin Nicolaevich, doctor of technical sciences, \\ professor of Psychology and Pedagogy Department \\ Ryabinova Elena Nicolaevna, doctor of pedagogical sciences, \\ professor of Higher Mathematics and Application-Oriented Informatics Department \\ Samara State Technical University (Samara, Russian Federation)
}

\begin{abstract}
The paper contains successful pedagogical experience of Samara State Technical University in the field of exceptional children's advanced and accelerated training. On the basis of this experience possibilities of the advanced and accelerated training are analyzed. This kind of training is considered to be one of the most effective ways of gifted youth's development. On the basis of the available theoretical and practical experience the authors note that technical universities with their multilevel structures of higher education can become very effective intellectual centers of the integrated systems of continuous education, including various educational institutions of pre-university and additional postgraduate training. The paper contains experience of an integrated educational system of continuous and differentiated (on abilities) education «School - HEI» in homogeneous groups. It is shown that training of gifted students in groups with equal mental capacities favorably influences their self-assessment and they in such situation should study wholeheartedly forces, feeling continuous stimulation from schoolmates. Characteristics of capacity of the academic college as the associated educational institution of the new type functioning on the basis of organizational and methodical merging of the university and school and at the same time being structural division of both founders are given as an example. It is noted that the considered models of structures of the integrated educational systems possess various degree of intensity of training, in communication with what rationing of average loading of students in the academic college acquires the special importance and relevance. Proceeding from the standard maximum permissible week educational loading of the young man caused by his psychophysiological opportunities, social conditions and cultural requirements the technique of her flexible rationing which efficiency is confirmed with long-term monitoring of the graduates of the academic college who have become subsequently successful scientists, inventors, experts is described.
\end{abstract}

Keywords: gifted students; integrated educational system; academic college; flexible standardization methodology; intensity of training.

УДК 37.07

\section{СОДЕРЖАТЕЛЬНЫЕ АСПЕКТЫ РАЗРАБОТКИ СТРАТЕГИЙ И ПРОЕКТОВ МУНИЦИПАЛЬНЫХ ОРГАНОВ УПРАВЛЕНИЯ ОБРАЗОВАНИЕМ}

(C) 2017

Фишман Лев Исаакович, доктор экономических наук, доктор педагогических наук, профессор, декан факультета экономики, управления и сервиса

Иванов Михаил Юрьевич, доктор экономических наук, доцент, заведующий кафедрой экономики Самарский государственный сочиально-педагогический университет (2. Самара, Российская Федераџия)

Аннотация. В данной статье представлены теоретические подходы к разработке стратегий и проектов муниципальных органов управления образованием. Рассмотрение муниципальной системы образования как территориально-отраслевой комплекса, структурно изоморфного холдингу, позволило определить институциональную роль муниципального органа управления образованием как аналог управляющей компании холдинга, а учреждения и организации, непосредственно оказывающие образовательные услуги, как производственные подразделения холдинга. Выявление специфики связей муниципального органа управления (управляющей подсистемы) и непосредственных производителей образовательных услуг (управляющей подсистемы) позволило выявить функции муниципального органа управления образованием, который ставит задачи перед производителями образовательных услуг, входящими в территориально-отраслевой комплекс, и обеспечивает реализацию этих задач соответствующими ресурсами. Построена классификация ресурсов, которые являются объектами управления головной организации территориально-отраслевого комплекса: организационные ресурсы, финансовые ресурсы, кадровые ресурсы, ресурс формирования общественного мнения, информационный ресурс. На основе данной классификации сгруппированы механизмы управления по признаку однородности объектов управления: механизмы оптимизации структуры сети организацийпроизводителей услуг, механизмы финансирования организаций-производителей услуг, механизмы работы с кадрами организаций-производителей услуг, механизмы взаимодействия организаций-производителей услуг с субъектами внешней среды, механизмы контроля функционирования и мониторинга в муниципальной системе образования. При этом задачи муниципальных стратегий, конкретные цели муниципальных проектов должны быть связаны с модернизацией данных механизмов. 
Ключевые слова: муниципальные стратегии и проекты; территориально-распределенные производственные структуры холдингового типа; территориально-отраслевой комплекс образовательных услуг; функции муниципального органа управления образованием; ресурсы управления; механизмы управления в территориально-отраслевом комплексе образовательных услуг.

Федеральный закон от 28.06.2014 № 172-Ф3 «О стратегическом планировании в Российской Федерации» установил основы стратегического планирования в Российской Федерации. В большинстве муниципальных районов и городских округов разрабатываются стратегии социально-экономического развития соответствующих муниципальных образований, различные проекты, которые страдают существенными недостатками. Среди дефектов стратегий, подготовленных органами местного самоуправления, можно назвать отсутствие в стратегиях задач, которые для достижения целей развития должен решать собственно орган местного самоуправления (администрация), а среди дефектов проектов - почти полное отсутствие таковых, имеющих целью изменение механизмов, которые орган местного самоуправления должен использовать для реализации стратегий. Все это в полной мере относится к муниципальным системам образования.

Анализ публикаций позволяет утверждать, что в подавляющем большинстве работ либо констатируется важность разработки муниципальных стратегий и проектов, ставятся в наиболее общем виде задачи стратегического планирования социально-экономического развития муниципальных образований без проработки содержания стратегических документов, либо калькируются фрагменты подходов к построению бизнес-стратегий и бизнес-проектов, которые, по понятным причинам, не могут быть напрямую перенесены в сферу муниципального управления. Таким образом, анализ содержательных аспектов осуществления стратегического планирования и разработки проектов в деятельности муниципальных органов управления образованием представляется актуальным как в теоретическом, так и в практическом плане.

Анализ главы 3 Федерального закона «Об общих принципах организации местного самоуправления в Российской Федерации» (от 6 октября 2003 года $\mathrm{N}$ 131-Ф3) показывает, что полномочия органа местного самоуправления предусматривают организацию предоставления гражданам ряда образовательных услуг. Заметим, что данные услуги получают жители муниципального образования, производителями услуг оказываются сегодня муниципальные учреждения, организации, предприятия, а также частные юридические и физические лица (в зависимости от способа организации предоставления услуг) отрасли образования, поэтому производителей таких услуг можно рассматривать в контексте концепций территориально-отраслевых комплексов: как в качестве средообразующих групп предприятий, объединенных и территориально, и по отраслевому принципу, так и по принципу социальной инфраструктуры территории.

Отметим, что современные авторы рассматривают преимущественно территориально-отраслевые комплексы промышленного характера. Так, О.М. Трофимова отмечает, что «содержательно территориально-отраслевая система (комплекс) представляет собой совокупность функционально взаимосвязанных отраслевых и территориальных экономических подсистем. Главным критерием данной системы является комплексность, предполагающая взаимосвязь, взаимозависимость и взаимообусловленность всех структурных элементов хозяйства региона. При этом данная система подчиняется требованиям иерархичности, что на практике отражается в формировании отдельных элементов отраслевого комплекса не только на уровне региона, но и на уровне районов областного значения, территорий, муниципалитетов, промышленных узлов, промышленных центров и промышленных пунктов» [цит. по 1].

Н.Н. Пересторониной в рамках исследования механизмов управления легкой промышленностью предложена организационная структура взаимодействия предприятий, входящих в состав территориально-отраслевого комплекса подотраслей легкой промышленности, раскрыта сущность регионального управления территориально-отраслевыми образованиями и проанализированы проблемы функционирования территориально-производственных комплексов [2]. А.В. Ивануса исследовал закономерности управления территориально-отраслевым лесопромышленным комплексом [3].

Территориально-отраслевые комплексы применительно к услугам изучают специалисты в области управления городским хозяйством: «городское хозяйство представляет собой территориально-отраслевой комплекс, обеспечивающий потребности населения или территории в услугах, работах и продукции, имеющих общественную значимость, а также создающий необходимые условия для развития сферы обслуживания в городе» $[4$, с. 4$]$.

Н.Н. Минаев предпринял попытку изучения структуры городского хозяйства в разрезе территориально-отраслевых комплексов, сконцентрировав свои усилия на жилищно-коммунальном хозяйстве как одном из таких комплексов. Анализ структуры городского хозяйства автором, в частности, показал, что в числе ее элементов имеется социальная инфраструктура, которая состоит из отраслей физической культуры и спорта, культуры, образования, здравоохранения [5, с. 3]. Подобной точки зрения придерживается И.В. Омельченко, который считает, что инженерная инфраструктура коммунального хозяйства города представляет собой сложный территориально-отраслевой комплекс, включающий совокупность технических объектов и выполняющий жизненно важные функции по обеспечению потребителей энергетическими и водными ресурсами, средствами связи, информацией, маршрутной сетью, транспортными перевозками и другими услугами [1]

Д.В. Гирийчук в рамках разработки механизмов управления туристической отраслью уточнил понятие территориально-отраслевого комплекса туристско-рекреационных услуг и разработал теоретические и методические основы управления территориальным туристско-рекреационным комплексом посредством его структурной, территориальной и управленческой реорганизации [6].

К.А. Омарова в рамках исследования государственного регулирования развития социальной инфраструктуры региона уточнила содержание понятия 
«социальная инфраструктура региона», которая рассматривается как территориально-отраслевой комплекс, обеспечивающий социально-пространственные условия воспроизводства рабочей силы и социальной защиты населения через оказание взаимосвязанных, но не взаимозаменяемых услуг населению в форме социально-значимой деятельности [7].

Представляется обоснованным придерживаться того понимания территориально-отраслевого комплекса, которое прямо содержит его существенные признаки и дает возможность определить структуру комплекса [8].

Таким образом, в рамках территориально-отраслевого подхода орган местного самоуправления можно рассматривать как элемент территориальноотраслевого комплекса определенных (прежде всего - социальных) услуг и благ, обеспечивающий управление (в широком смысле подразумевающим и регулирование) оказанием этих услуг и предоставлением благ.

Проиллюстрируем данную логику на примере отрасли образования. Федеральный закон «Об образовании» (ст. 10) определяет систему образования как совокупность взаимодействующих:

- преемственных образовательных программ различных уровня и направленности, федеральных государственных образовательных стандартов и федеральных государственных требований;

- сети реализующих их образовательных учреждений и научных организаций;

- органов, осуществляющих управление в сфере образования, и подведомственных им учреждений и организаций;

- объединений юридических лиц, общественных и государственно-общественных объединений, осуществляющих деятельность в области образования.

Отталкиваясь от определения территориальноотраслевого комплекса получим, что территориально-отраслевой комплекс образовательных услуг состоит из государственных (муниципальных) органов, осуществляющих управление в сфере образования, и подведомственных им учреждений и организаций, расположенных на территории региона (муниципалитета).

На практике непосредственное оказание образовательных услуг происходит, прежде всего, государственными (муниципальными) учреждениями (детскими садами, школами и проч.), находящимися в ведении соответствующих муниципальных органов управления (муниципальных отделов образования и пр.).

Муниципальный орган управления образованием может содействовать удовлетворению образовательных потребностей граждан и достижению определенных социальных эффектов не только через подведомственные учреждения, но и путем координации деятельности с иными - не подчиняющимися муниципалитету напрямую - существующими производителями образовательных услуг (например, федеральными, региональными, частными), путем стимулирования создания новых производителей таких услуг, в частности работающих на средства благотворителей (например, частных школ). Такие действия позволят увеличить объем производства образовательных услуг, необходимых для удовлетворения потребностей граждан, и создавать необходимые социальные эффекты без увеличения объема финансирования отрасли из муниципального бюджета.
В связи с этим представляется целесообразным определение институциональной роли муниципального органа управления образованием в рассматриваемом территориально-отраслевом комплексе в рамках общей теории построения организационных систем. Важным обстоятельством, требующим учета при определении места муниципального органа управления образованием, является тот факт, что территориально-отраслевой комплекс не является моноорганизацией. На наш взгляд, орган управления территориально-отраслевым комплексом образовательных услуг вместе с сетью производителей таких услуг фактически представляет собой институциональную единицу типа холдинга.

Под холдингом (от англ. holding - владеющий) традиционно понимается акционерная компания, использующая свой капитал для приобретения контрольных пакетов акций других компаний с целью установления господства и контроля над ними [9, с. 1728]. В.А. Лаптев [10, с. 55], Е.Н. Кравченко [11], С.Н. Кушаков [12, с. 7-10], И.С. Шиткина [13, с. 13] определяют холдинг как совокупность взаимосвязанных участников (хозяйствующих субъектов), осуществляющих совместную деятельность, четко разводя понятия «холдинг» и «холдинговая компания»: «под холдингом будем понимать структурированную организацию юридических лиц, одно из которых (холдинговая компания) имеет возможность оказывать влияние на решения остальных участников холдинга (дочерних компаний)» [11].

Иностранные авторы, в частности Т. Келлер, определяя понятие холдинга (холдинговой компании) указывает еще на два аспекта функционирования данного вида крупных интегрированных структур. Первый аспект раскрывает позицию портфельного инвестора в конгломерат предприятий, второй управленческую позицию инвестора: «под холдингом или холдинговой компанией следует понимать предприятие, главной областью деятельности которого является рассчитанное на длительный срок долевое участие в одном (или нескольких) самостоятельных в производственном отношении других предприятиях, ... если позволяет объем вложенного капитала (денежного капитала или ценных бумаг), холдинг может выполнять наряду с управленческими функциями и функциями финансирования также функции управления (менеджмента) основным обществом концерна и зависимыми предприятиями» $[14$, c. 17$]$. При этом определение холдинга позволяет выделить два его основных признака:

1) контроль и управление холдинговой компанией за дочерними и зависимыми компаниями;

2) наличие хозяйственной самостоятельности, не связанной с деятельностью холдинга, у участников холдинга $[15$, с. 50,55$]$.

Первый признак указывает на управленческий характер деятельности холдинговой компании, она является в холдинге субъектом управления, второй что все участники холдинга обладают статусом юридического лица, третий - указывает на средства, позволяющие достичь цели создания холдинга.

Важным в связи с вышеизложенным представляется анализ моделей взаимодействия головной компании и входящих в состав холдинга предприятий. Различные модели взаимодействия формируются на основе разграничения управленческих полномочий, функций, задач между головной компанией и дочер- 
ними хозяйственными обществами. При этом данное разграничение может базироваться, например, на следующих принципах:

- все функции, относящиеся к хозяйственной деятельности, возлагаются на дочерние общества холдинга;

- все функции по доходам холдинга должны выполняться холдингом;

- каждое хозяйственное общество холдинга исполняет свои специфические функции [16, с. 96].

Исходя из экономической структуры холдинга, основным направлением в управлении им являются разработка и осуществление стратегии холдинга. Отмечая, что степень самостоятельности предприятий может быть закреплена в договоре между головной компанией и предприятием и существенно различаться в зависимости от отрасли, обычаев делового оборота, социально-экономической ситуации и других факторов, К.Я. Портной выделяет так называемые «неделегируемые» подчиненным предприятиям функции: «проведение необходимых мероприятий по получению, обработке и передаче информации, организация периодических отчетов, запрос и подготовка плановых показателей для хозяйственных обществ; контроль за ходом оперативной хозяйственной деятельности и проведение контроля за общими результатами; участие, а также задачи проверки и контроля при составлении годовых балансов» $[16$, с. 95]. В частности, важнейшим инструментом управления является кадровая стратегия: назначение и освобождение от должностей руководителей (и членов коллективных органов управления) дочерних предприятий. Однако холдинговая компания не ограничивает автономию дочерних обществ в принятии решений в их повседневной хозяйственной деятельности» [16, с. 95].

На наш взгляд, муниципальный орган управления образованием как организатор деятельности своеобразного территориально-отраслевого комплекса производства услуг для населения может рассматриваться как макроорганизация, структурно изоморфная холдингу (по крайней мере, в управленческом аспекте) исходя из следующих соображений.

1) Сетевая структура территориально-отраслевого комплекса.

Рассматривая структуру сети производителей образовательных услуг, нетрудно заметить признаки как горизонтальной, так и вертикальной интеграции (например, элементы сети образовательных учреждений выстроены по принципу полного цикла оказания услуг как учреждения разного уровня образования).

2) Орган управления территориально-отраслевым комплексом (в данном случае муниципальный орган управления образованием), как и головная компания холдинга, институционально отделен от производственных подразделений, не располагает собственной производственной базой, не занимается собственно производственной деятельностью.

Муниципальный орган управления образованием выполняет функции, сходные с функциями головной компании холдинга, закрепленные, как правило, в законодательных актах, уставах подведомственных учреждений и договорах между органами управления и производителями услуг:

- структурные функции (принятие решений о создании, ликвидации, реорганизации учреждений- производителей образовательных услуг), что обеспечивает адаптацию структуры территориальной сети производителей услуг к изменяющимся условиям (демографическим, социокультурным и проч.);

- функция целевого распределения финансовых ресурсов (бюджетное финансирование производителей образовательных услуг, в некоторых случаях утверждение их годовых финансовых планов (смет, бюджетов));

- функции кадрового менеджмента (аттестация и назначение руководителей подведомственных учреждений-производителей образовательных услуг);

- экспертно-аналитические функции (запрос, обработка и передача информации, система периодических отчетов о деятельности производителей образовательных услуг, разработка и утверждение показателей эффективности и результативности их деятельности);

- функции контроля за производственной и финансово-хозяйственной деятельностью производителей образовательных услуг (включая лицензирование отдельных видов деятельности, оценку качества оказываемых услуг), в том числе плановые и внеплановые инспекции, рассмотрение обращений потребителей, содержащих жалобы на качество услуг и представлений компетентных органов).

При этом орган управления комплексом может выстраивать взаимодействие с иными (не входящими в комплекс) производителями однородных услуг подобно тому, как головная компания холдинга может заказывать производство однородных продуктов или вступать в соглашения с такими производителями Понятно, что при этом объем перечисленных выше функций относительно таких независимых от органа управления производителей уменьшается.

Таким образом, проведенный анализ показывает целесообразность рассмотрения муниципального органа управления образованием (в части производства услуг за счет средств бюджета муниципалитета) как структурно изоморфного территориально-распределенным производственным структурам холдингового типа по отношению к учреждениям и организациямпроизводителям услуг, т.е. системам, в которых управляющие компании институционально отделень от непосредственных производителей товаров (услуг).

Иными словами, муниципальный орган управления образованием не управляет процессом производства услуг, этим занимаются руководители соответствующих учреждений и организаций, как подведомственных, так и не подведомственных муниципальному органу управления образованием. Точно так же, как руководители Газпрома или Лукойла не управляют процессом добычи, транспортировки, переработки газа или нефти: этим занимаются руководители производственных компаний, входящих в холдинг или работающих с холдингом в режиме производственного аутсорсинга. Муниципальный орган управления образованием ставит задачи перед производителями услуг, входящими в территориально-отраслевой комплекс, и обеспечивает реализацию этих задач соответствующими ресурсами.

Выявление данной специфики деятельности муниципального органа управления образованием как головной компании своеобразного территориальноотраслевого комплекса производства услуг позволяет осуществить конкретизацию направлений модернизации деятельности органов местного самоуправле- 
ния и - одновременно - определить содержательные ориентиры постановки стратегических задач для достижения целей социально-экономического развития муниципальных систем образования и тематические поля различных муниципальных проектов, призванных обеспечить реализацию подобных стратегий. Данные направления должны отражать модернизацию специфических механизмов управления территориально-отраслевым комплексом, то есть механизмы субъекта управления сложной в организационном отношении структурой, состоящей из множества автономных производственных подразделений, а не механизмы управления производственным процессом в организациях - производителях образовательных услуг.

Для решения данной задачи представляется необходимым раскрытие содержания понятия «механизм управления». Под механизмом вообще в научной литературе принято понимать следующее: «система, устройство, определяющее порядок какого-либо вида деятельности» $[17$, с. 283]. Более узким понятием является «механизм управления», который, например, по мнению Д.А. Новикова, можно определить как совокупность процедур принятия управленческих решений, этот же автор отмечает, что «с этой точки зрения механизм управления можно рассматривать как синоним метода управления, так как и тот и другой определяют, как осуществляется управление» [18, с. 67-68].

В научной литературе приведены различные подходы к классификации механизмов управления. Нас, в частности, интересуют механизмы управления сложными в организационном отношении системами, в связи с чем актуальными для данного проекта являются механизмы субъекта управления структурой, состоящей из множества автономных производственных подразделений.

Так, специалистами в области управления сложными многоэлементными системами выделяются: механизмы стимулирования персонала [19-21], механизмы распределения ресурсов (в смысле факторов производства) [22; 23], механизмы экспертизы [24; 25], механизмы внутрифирменных цен [26; 27], конкурсные механизмы [23], механизмы обмена ресурсами, механизмы «затраты-эффект» [23], механизмы смешанного финансирования проектов [1;28], механизмы агрегирования информации [29-31], механизмы самоокупаемости $[1 ; 32]$, механизмы назначения исполнителей $[1 ; 33,34]$, механизмы синтеза организационной структуры [31;35-38], механизмы комплексного оценивания [1;23], механизмы опережающего самоконтроля $[1 ; 39]$, противозатратные механизмы, механизмы страхования [1;40], механизмы взаимодействия с поставщиками, потребителями, государством [28].

Представляется необходимым классифицировать механизмы муниципального органа управления образованием в соответствии с объектами управления ресурсами, находящимися в его распоряжении. Отметим, что в научной литературе присутствует значительное количество развернутых классификаций ресурсов управленческой деятельности. При этом, как правило, выделяются: материально-технические ресурсы (основные и оборотные средства предприятий), финансовые ресурсы, кадровые ресурсы, информационные ресурсы, организационные ресурсы, ресурс формирования общественного мнения, инновационный ресурс, административный ресурс и проч.

В контексте решения задачи классификации механизмов управления, используемых муниципальным органом управления образованием, представляют интерес те ресурсы, которые являются объектами управления головной организации территориальноотраслевого комплекса (последовательность ресурсов произвольная):

- организационные ресурсы;

- финансовые ресурсы;

- кадровые ресурсы;

- ресурс формирования общественного мнения;

- информационный ресурс.

Данная классификация позволяет сгруппировать механизмы управления по признаку однородности объектов управления (ресурсов), например, следующим образом (табл. 1):

Таблица 1 - Классификация механизмов управления муниципального органа управления по признаку однородности объектов управления образованием

\begin{tabular}{|c|c|}
\hline $\begin{array}{l}\text { Механизмы оптимиза- } \\
\text { ции структуры сети } \\
\text { организаций- } \\
\text { производителей услуг }\end{array}$ & $\begin{array}{l}\text { Механизмы распределения } \\
\text { ресурсов. } \\
\text { Механизмы обмена ресур- } \\
\text { сами. } \\
\text { Механизмы назначения } \\
\text { исполнителей. } \\
\text { Механизмы синтеза орга- } \\
\text { низационной структуры. }\end{array}$ \\
\hline $\begin{array}{l}\text { Механизмы финанси- } \\
\text { рования организаций- } \\
\text { производителей услуг }\end{array}$ & $\begin{array}{l}\text { Механизмы внутрифир- } \\
\text { менных цен (в видоизме- } \\
\text { ненном для ОМС виде). } \\
\text { Конкурсные механизмы. } \\
\text { Механизмы «затраты-- } \\
\text { эффект». } \\
\text { Механизмы смешанного } \\
\text { финансирования проектов. } \\
\text { Механизмы самоокупае- } \\
\text { мости. } \\
\text { Противозатратные меха- } \\
\text { низмы. }\end{array}$ \\
\hline $\begin{array}{l}\text { Механизмы работы с } \\
\text { кадрами организаций- } \\
\text { производителей услуг }\end{array}$ & $\begin{array}{l}\text { Механизмы стимулирова- } \\
\text { ния персонала. }\end{array}$ \\
\hline $\begin{array}{l}\text { Механизмы взаимо- } \\
\text { действия организаций- } \\
\text { производителей с } \\
\text { субъектами внешней } \\
\text { среды }\end{array}$ & $\begin{array}{l}\text { Механизмы взаимодей- } \\
\text { ствия с поставщиками, по- } \\
\text { требителями, государ- } \\
\text { ством. }\end{array}$ \\
\hline $\begin{array}{l}\text { Механизмы контроля } \\
\text { функционирования и } \\
\text { мониторинга в муни- } \\
\text { ципальной системе } \\
\text { образования }\end{array}$ & $\begin{array}{l}\text { Механизмы экспертизы. } \\
\text { Механизмы комплексного } \\
\text { оценивания. } \\
\text { Механизмы опережающе- } \\
\text { го самоконтроля. }\end{array}$ \\
\hline
\end{tabular}

Данная классификация групп специфических механизмов управления позволяет раскрыть направления модернизации деятельности муниципального органа управления образованием.

В частности, оптимизация структуры сети должна обеспечивать структурные изменения в сетях производителей образовательных услуг, которые должны служить ресурсом для достижения новых целей. При этом должны обеспечиваться доступность и качество услуг. 
Модернизация механизмов финансирования должна ориентировать организации на производство качественных (в частности, соответствующих запросам граждан) образовательных услуг при эффективном использовании ресурсов.

Модернизация механизмов взаимодействия производителей услуг с субъектами внешней среды предполагает формирование партнерских отношений производителей образовательных услуг и муниципального органа управления образованием с различными местными сообществами (включая общественные организации), группами населения через последовательную передачу этим сообществам права принятия решений. Эта передача должна обеспечивать повышение качества образовательных услуг путем создания механизмов трансформации запросов субъектов внешней среды в заказ.

Модернизация механизмов контроля функционирования и мониторинга в территориальном комплексе предполагает изменение механизмов контроля и мониторинга качества образовательных услуг, в частности ориентацию контрольно-измерительных процедур на сбор информации, отражающей степень достижения целей и задач модернизации сферы оказания образовательных услуг.

Модернизация механизмов работы с кадрами производителей образовательных услуг должна исходить из того, что любые механизмы работы с персоналом должны обеспечивать: подбор кадров, способных обеспечить реализацию целей организации, соответствие квалификации имеющихся кадров целям организации и утилизацию кадров, не способных обеспечить реализацию целей организации.

Таким образом, муниципальный орган управления образованием сам не производит услуги для населения, его деятельность связана с организацией и стимулированием производства определенных образовательных услуг в определенных частях муниципалитета рациональными способами (доступность, качество и эффективность), а функции муниципального органа управления образованием состоят в постановке содержательных целей (стратегических целей развития муниципальной системы образования, общие цели муниципальных проектов) перед подведомственной системой и иными потенциальными производителями образовательных услуг и модернизации ресурсов (в широком смысле этого термина), обеспечивающей реализацию целей. При этом стратегические задачи, конкретные цели муниципальных проектов должны быть связаны с названной модернизацией ресурсов. Иными словами, важно, чтобы достижение содержательных целей, связанных с новыми требованиями и новыми запросами граждан, обеспечивалось модернизацией ресурсов, к приоритетным направлениям которой относятся:

- модернизаиия организаиионно-финансовых механизмов при производстве образовательных услуг: целевое финансирование качественных (т.е. адекватных запросам конечных потребителей и приоритетам муниципалитета) образовательных услуг и реализации абсолютно необходимых с точки зрения самой возможности оказания услуг функций, а не деятельности учреждений как таковой (включая реализацию их внутренних функций), создание конкурентной среды (там, где это возможно) среди подведомственных учреждений и иных производителей услуг, привлечение ресурсов, в том числе посредством координации и стимулирования деятельности иных, непод- ведомственных муниципальному органу управления образованием производителей образовательных услуг;

- модернизаиия механизмов взаимодействия отрасли образования и отдельных ее элементов с внешней средой (передача полномочий принятия важных решений субъектам внешней среды для повышения качества услуг и привлечения в отрасли дополнительных ресурсов, согласование и стимулирование деятельности иных производителей образовательных услуг без использования средств муниципального бюджета);

- модернизация структуры сети производителей образовательных услуг: изменение - в случае необходимости - структурных элементов сети производителей, номенклатуры производимых ими образовательных услуг, фокусирования учреждений на производство определенных услуг, привлечение иных (кроме подведомственных учреждений) производителей услуг за счет средств муниципального бюджета, согласование и стимулирование деятельности иных производителей услуг без использования средств бюджета муниципалитета;

-модернизачия информачионных (контрольных) механизмов в отрасли образования (минимизация и целевая ориентация информационных потоков, задание - в необходимых случаях - индикаторов качества образовательных услуг и деятельности производителей услуг);

-модернизация механизмов работы с кадрами в отрасли образования (приведение кадрового ресурса в соответствие с ее новыми задачами через изменение взаимодействия с учреждениями, готовящими кадры для отрасли, систем оплаты труда, повышения квалификации, аттестации кадров).

Данные направления модернизации должны рассматриваться как взаимодополняющие ресурсы: решение задач по одному из приоритетов облегчит решение задач по другому (или другим) приоритетам, либо будет стимулировать реализацию других приоритетов. Поэтому органу местного самоуправления целесообразно ставить взаимосвязанные стратегические задачи и осуществлять взаимосвязанные проекты, позволяющие модернизировать названные механизмы, без чего невозможна эффективная реализация содержательных целей стратегии развития муниципальной системы образования.

\section{СПИСОК ЛИТЕРАТУРЫ:}

1. Омельченко И.В. Программно-целевое управление развитием инженерной инфраструктуры города: дис. ... канд. экон. наук. СПб., 1999. 200 с.

2. Пересторонина Н.Н. Управление развитием территориальных комплексов в проблемных отраслях региона (на примере Кировской области): дис. ... канд. экон. наук. Киров, 2005. 224 с.

3. Івануса А.В. Оптимізація виробничих зв'язків підприємств територіального лісопромислового комплексу за критеріями еколого-економічної ефективності (на прикладі Львівської області): автореф. дис. ... канд. екон. наук. Львов, 2003. 20 с.

4. Чекалин В.С. Экономика городского хозяйства / В.С. Чекалин. СПб.: Гос. инженерно-экон. акад., 1999. $166 \mathrm{c}$.

5. Минаев Н.Н. Управление жилищно-коммунальным комплексом города: территориально-отраслевой аспект: автореф. дис. ... д-ра экон. наук. Челябинск, $2010.33 \mathrm{c}$. 
6. Гирийчук Д.В. Формирование механизма управления территориальным туристско-рекреационным комплексом в условиях рынка: дис. ... канд. экон. наук. Сочи, 2003. 188 с.

7. Омарова К.А. Государственное регулирование развития социальной инфраструктуры региона: на примере Республики Дагестан: дис. ... канд. экон. наук. Махачкала, 2006. 205 с.

8. Цветков А.В. Стимулирование в управлении проектами. М.: Апостроф, 2001. 143 с.

9. Российский энциклопедический словарь: в 2 т. / гл. ред. А.М. Прохоров. М., 2001. Т. 2. 2015 с.

10. Лаптев В.А. Предпринимательские объединения: холдинги, финансово-промышленные группы, простые товарищества. М.: Волтерс Клувер, 2008. $192 \mathrm{c}$.

11. Кравченко Е.Н. Такие разные холдинги [Электронный ресурс] // Учет. Налоги. Право. 2000. № 17. - http://jurisconsult.ru.

12. Кушаков С.Н. Повышение эффективности управления деятельностью экономических подразделений промышленного холдинга: дис. ... канд. экон. наук. М., 2001. 182 c.

13. Шиткина И.С. Холдинги: Правовое регулирование экономической зависимости. Управление в группах компаний. М.: Волтерс Клувер, 2008. 560 с.

14. Келлер Т. Концепции холдинга. Организационные структуры и управление / пер. с нем. Н.М. Двухшерстковой; под общ. ред. Ю.П. Руднева, Р.М. Гринева. Обнинск, 1996. 311 с.

15. Рубцов С.В. Целевое управление в корпорациях. Управление изменениями. М.: Феникс, 2001. $256 \mathrm{c}$.

16. Портной К.Я. Правовое положение холдингов в России: науч.-практ. пособие. М.: Волтерс Клувер, 2004. 304 c.

17. Управление социальной сферой: учебник / под ред. В.Э. Гордина. СПб.: ГУЭФ, 1998. 289 с.

18. Новиков Д.А., Иващенко А.А. Модели и методы организационного управления инновационным развитием фирмы. М.: Ленанд, 2006. 332 с.

19. Новиков Д.А. Теория управления организационными системами. 2-е издание. М.: Физматлит, 2007. $584 \mathrm{c}$.

20. Новикова К.Н., Мкртумова И.В. Типология управленческих ресурсов системы социальной защиты // Вестник ТИСБИ. 2001. № 2. С. 212-220.

21. Чекалин В.С. Экономика городского хозяйства. СПб.: Гос. инженерно-экон. акад., 1999. 166 с.

22. Бурков В.Н., Горгидзе И.И., Новиков Д.А., Юсупов Б.С. Модели и механизмы распределения затрат и доходов в рыночной экономике. М.: ИПУ РАН, 1997. $61 \mathrm{c.}$

23. Новиков Д.А. Управление проектами: организационные механизмы. М.: ПМСОФТ, 2007. 140 с.

24. Бурков В.Н., Новиков Д.А. Как управлять проектами. М.: Синтег, 1997. 188 с.

25. Петраков С.Н. Механизмы планирования в активных системах. М.: ИПУ РАН, 2001. 135 с.

26. Новиков Д.А., Цветков А.В. Механизмы стимулирования в многоэлементных организационных системах. М.: Апостроф, 2000. 182 с.

27. Караваев А.П. Модели и методы управления составом активных систем. М.: ИПУ РАН, 2003. $151 \mathrm{c}$.

28. Новиков Д.А., Петраков С.Н. Курс теории активных систем. М.: Синтег, 1999. 104 с.

29. Балахонов А.Л. Формирование современных организационно-управленческих структур на предприятиях строительного комплекса: автореф. дис. ... канд. экон. наук. СПб., 2007. 20 с.

30. Коновальчук Е.В., Новиков Д.А. Модели и методы оперативного управления проектами. М.: ИПУ РАН, 2004. $63 \mathrm{c}$.

31. Новиков Д.А. Сетевые структуры и организационные системы. М.: ИПУ РАН, 2003. 102 с.

32. Бурков В.Н., Заложнев А.Ю., Новиков Д.А. Теория графов в управлении организационными системами. М.: Синтег, 2001. 124 с.

33. Балашов В.Г., Заложнев А.Ю., Иващенко А.А., Новиков Д.А. Механизмы управления организационными проектами. М.: ИПУ РАН, 2003. 84 с.

34. Щепкин А.В. Механизмы внутрифирменного управления. М.: ИПУ РАН, 2001. 80 с.

35. Воронин А.А., Мишин С.П. Оптимальные иерархические структуры: монография. М.: ИПУ РАН, $2003.214 \mathrm{c}$.

36. Губко М.В. Математические модели оптимизации иерархических структур. М.: Ленанд, 2006. $264 \mathrm{c}$.

37. Новиков Д.А. Механизмы функционирования многоуровневых организационных систем. М.: Фонд «Проблемы управления», 1999. $161 \mathrm{c.}$

38. Новиков Д.А. Стимулирование в организационных системах. М.: Синтег, 2003. 182 с.

39. Колосова Е.В., Новиков Д.А., Цветков А.В. Методика освоенного объема в оперативном управлении проектами. М.: Апостроф, 2001. 156 с.

40. Бурков В.Н., Заложнев А.Ю., Кулик О.С., Новиков Д.А. Механизмы страхования в социальноэкономических системах. М.: ИПУ РАН, 2001. 109 с.

\section{SUBSTANTIAL ASPECTS OF MUNICIPAL EDUCATION BODIES STRATEGIES AND PROJECTS DEVELOPMENT}

(C) 2017

Fishman Lev Isaakovich, doctor of economical sciences, doctor of pedagogical sciences, professor, head of Economics, Management and Service Faculty

Ivanov Mikhail Yurievich, doctor of economical sciences, associate professor, head of Economics Department Samara State University of Social Sciences and Education (Samara, Russian Federation)

Abstract. Theoretical approaches to municipal education bodies' strategies and projects development are presented in this paper. The conceptualization of municipal system of education as territorial-sectoral complex which is structurally isomorphic to holding helps to understand institutional character of a municipal education body as similar to the character of management company while the position of schools and other organizations which provide education services as similar to the position of holding production units. Having studied the peculiarities of relationship 
of a municipal education body and schools we suggest the functions of municipal education body, which assigns tasks to schools and provides schools with different resources. We also suggest the classification of resources, which are the management objects of municipal education body: organizational resources, financial resources, human resources, public relations recourses and information resources. On this base we group the management mechanisms of municipal education body: the mechanisms of school and other organizations structure optimization, the mechanisms of schools and other organizations financing, the mechanisms of schools and other organizations human resources development, the mechanisms of schools and other organizations interaction with the subjects of the environment, the mechanisms of control and monitoring of a municipal system of education. That is why the objectives of municipal strategies and specific targets of municipal projects need to be connected with the modernization of these mechanisms.

Keywords: municipal strategies and projects; territorially distributed production structures; territorial-sectoral complex of education services; municipal education body functions; management resources; management mechanisms in a territorial-sectoral complex of education services.

\title{
О ГОТОВНОСТИ СТУДЕНТОВ ТЕХНИЧЕСКОГО ВУЗА К ФОРМИРОВАНИЮ ЭКОЛОГО-ОРИЕНТИРОВАННЫХ ЦЕННОСТЕЙ
}

(C) 2017

\author{
Холопов Юрий Александрович, кандидат сельскохозяйственных наук, доцент кафедры строительства \\ Слугина Анастасия Николаевна, студент факультета строительства железных дорог \\ и информационных технологий \\ Стиханова Светлана Алексеевна, студент факультета строительства железных дорог \\ и информационных технологий \\ Самарский государственный университет путей сообщения (г. Самара, Российская Федерация)
}

Аннотация. В статье рассматриваются вопросы, связанные с оценкой готовности студентов технического вуза к формированию основ экологической культуры. Подчеркнуто, что проблемы современного общества обусловлены длительным доминированием антропоцентрического отношения к природе. Увеличение антропогенной нагрузки часто основано на искусственном подогреве потребительского спроса. Показано, что формирование эколого-ориентированных ценностей невозможно только через образовательный процесс. Приведены данные социологического опроса 183 студентов Самарского государственного университета путей сообщения (СамГУПС) (133 юноши и 50 девушек) в возрасте от 17 до 22 лет, еще не изучавших экологию. Влияние студентов на окружающую среду оценено по методике «экологического следа», предложенной Уильямом Ризом в 1992 году: по уровню потребления и образу жизни лишь 16\% девушек и 20\% юношей вписываются в одну «условную планету». Отмечено, что ключевым моментом в формировании экологической культуры является выбор источников информации. Выявлены следующие закономерности обращения молодежной аудитории с информацией: студенты предпочитают в качестве источников информации телевидение и интернет-СМИ, но доверяют больше учебникам (84\% девушек и 70\% юношей); в современных СМИ экологическая информация представлена в минимальных объемах, что показывает потенциал развития данного механизма формирования экологической культуры. Девушек интересуют экологическая безопасность продуктов питания, жилья; решение вопросов экологии на уровне учебного заведения; экологические проблемы и их решения в регионе проживания. Юноши определили приоритетными следующие темы: деятельность общественных экологических организаций и движений; научные достижения в области экологии; глобальные экологические проблемы. Только 50\% опрошенных девушек и $37 \%$ юношей считают себя экологически образованными.

Ключевые слова: экологический след; экологическая информация; экологическая культура; социологический опрос; средства массовой информации; формирование экологического сознания; природоохранная деятельность; экологические проблемы; уровень потребления.

\section{Актуальность исследования}

Готовность к восприятию экологической информации, изучению экологии как учебной дисциплины и выполнению активных природоохранных действий могут во многом определить успех образовательной и просветительной деятельности, направленной на формирование эколого-ориентированных ценностей. Корректировки учебных планов и рабочих программ, основанных на стремительно меняющихся ФГОСах, порой не успевают учитывать особенности взаимосвязей предшествующих и последующих дисциплин, психолого-педагогические аспекты усвоения одних и тех же тем различным контингентом обучающихся (на сегодняшний день изучение экологии в нашем вузе может быть на 1, 2, 3, а иногда и на 4 курсе в за- висимости от специальностей и направлений подготовки).

На законодательном уровне определено: «В целях формирования экологической культуры и профессиональной подготовки специалистов в области охраны окружающей среды устанавливается система всеобщего и комплексного экологического образования, включающая в себя общее образование, среднее профессиональное образование, высшее образование и дополнительное профессиональное образование специалистов, а также распространение экологических знаний, в том числе через средства массовой информации, музеи, библиотеки, учреждения культуры, природоохранные учреждения, организации спорта и туризма» [1]. Однако далеко не в каждом 